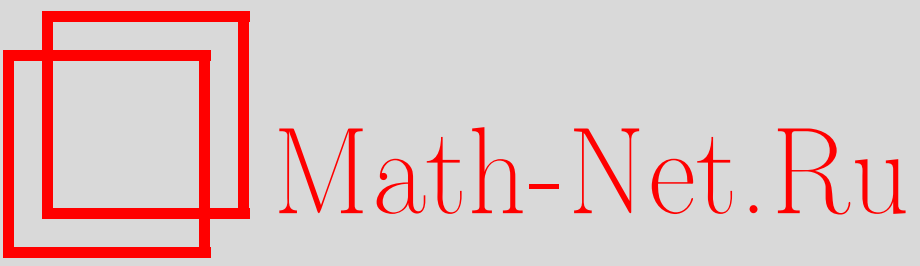

А. В. Проскурников, Ю. Р. Романовский, О регулярных триангуляциях невыпуклых многогранников, УМН, 2002, том 57, выпуск 4, 185-186

DOI: https://doi.org/10.4213/rm546

Использование Общероссийского математического портала Math-Net.Ru подразумевает, что вы прочитали и согласны с пользовательским соглашением

http://www.mathnet.ru/rus/agreement

Параметры загрузки:

IP : 3.81 .55 .215

26 апреля 2023 г., 13:16:03 


\title{
О РЕГУЛЯРНЫХ ТРИАНГУЛЯЦИЯХ НЕВЫПУКЛЫХ МНОГОГРАННИКОВ
}

\author{
А. В. Проскурников, Ю. Р. РОмАновСКИй
}

Триангуляцией многогранника называется его разбиение на симплексы, которые пересекаются между собой по целым граням. Важный класс триангуляций составляют регулярные, или когерентные, триангулящии [1]. В работе [2] приведен алгоритм описания всех регулярных триангуляций выпуклого многогранника. Мы обобщаем его на случай невыпуклых тел. Мы также обсуждаем вопрос о построении регулярных триангуляций невыпуклых тел с дополнительными точками (точками Штейнера).

Авторы благодарны С. В. Дужину за предложение заняться данной тематикой в рамках возглавляемого им проекта по вычислительной геометрии, а также за внимание к работе и обсуждение резултатов. Мы также считаем своим приятньм долгом поблагодарить Н.Е. Мнёва, обратившего наше внимание на теорию вторичных многогранников и снабдившего нас копиями ряда опубликованных по этой теории статей.

Пусть $\mathscr{A}=\left\{a_{1}, a_{2}, \ldots, a_{n}\right\}$ - набор $n$ точек в $\mathbb{R}^{d}$, а $\mathbb{R}^{\mathscr{A}} \simeq \mathbb{R}^{n}$-пространство вещественных функций на $\mathscr{A}$. Почти каждому вектору $\psi \in \mathbb{R}^{n}$ можно сопоставить триангуляцию $T=T(\psi)$ выпуклого (первичного) многогранника $\operatorname{conv}(\mathscr{A}) \subset \mathbb{R}^{d}$ построением выпуклой оболочки точек $\left(a_{i}, \psi_{i}\right) \in \mathbb{R}^{d+1}$ и проектированием ее нижней части на $\mathbb{R}^{d}$. Триангуляции, которые могут быть получены таким образом, называются регулярныцми. Векторы $\psi \in \mathbb{R}^{n}$, порождающие одну и ту же триангуляцию $T$, образуют конус $C(T)$. Семейство всех таких конусов $\mathscr{F}(\mathscr{A})$ называют вторичнылм веером. Теорема Гельфанда, Зелевинского и Капранова [1] утверждает, что существует вторичный многогранник $\Sigma(\mathscr{A}) \subset \mathbb{R}^{n}$ размерности $n-d-1$, нормальньй веер которого совпадает с $\mathscr{F}(A)$. Конструктивное геометрическое описание $\mathscr{F}(\mathscr{A})$, основанное на методе диаграмм Гейла, дано в работе Биллеры, Филлимана и Штурмфелса [2]. Мы исползуем технику работы [2] для решения следующей задачи. Дан набор $S$ симплексов (размерности не выше $d$ ) с вершинами в $\mathscr{A}$. Требуется либо найти вынужденную регулярную триангуляцию, т.е. такую регулярную триангуляцию $T$, что $S \subset T$, либо доказать, что ее не существует.

ТЕОРема 1. Задача о вынужденной регулярной триангуляции разрешима за время, полиномиально зависящее от $n$.

Алгоритм устроен следующим образом.

1. Находим преобразование Гейла $B=\left\{b_{1}, \ldots, b_{n}\right\}$ конфигурации $\mathscr{A}=\left\{a_{1}, \ldots, a_{n}\right\}$.

2. Для каждого симплекса $\sigma=\left\{\sigma_{1}, \ldots, \sigma_{k}\right\}$ (здесь $\sigma_{i}$-номера точек из $\mathscr{A}$, являющихся вершинами $\sigma)$ находим конус $C(\sigma)=\operatorname{cone}\left(b_{\sigma_{1}^{*}}, \ldots, b_{\sigma_{n-k}^{*}}\right)$, где $\sigma^{*}-$ дополнение к подмножеству $\sigma$ в $\{1, \ldots, n\}$.

3. Находим конус вынужденных триангуляций $C(S)=\cap C(\sigma)$ по всем $\sigma \in S$.

4. Если $C(S)=\varnothing$, то вынужденной регулярной триангуляции не существует. В противном случае фиксируем вектор $\psi \in C(S)$ и образуем триангуляцию $T=T(\psi)$.

Доказательство полиномиальности опирается на работу Л. Г. Хачияна [3].

Задача о вынужденной триангуляции имеет непосредственное отношение к задаче триангуляции невыпуклых тел. В самом деле, регулярной триангуляцией невыпуклого симплициального многогранника $P \subset \mathbb{R}^{3}$ назовем вьнужденную регулярную триангуляцию, отвечающую конфигурации $\mathscr{A}$ его вершин и набору $S$ его граней. В этом случае указанньй алгоритм проверит регулярную триангулируемость $P$ без использования точек Штейнера. Подчеркнем, что при отказе от условия регулярности такая проверка становится NP-полной задачей [4]. Кроме того, условие регулярности вносит большую специфику в задачу триангуляции с использованием точек Штейнера. Оказывается, что если $P$ нельзя регулярно триангулировать без точек Штейнера, то его нельзя регулярно триангулировать без добавления точек Штейнера на границу.

Работа выполнена при финансовой поддержке компании Шлюмберже. 
ТеОРема 2. Пусть $P$ - произвольный (не обязательно выпукльй) $d$-мерный многогранник, вершины которого содержатся в $\mathscr{A}$. Если существует регулярная триангуляция $P$ с вершинами в $\mathscr{A}$, то существует регулярная триангуляция $P$ с вершинами в $\mathscr{A} \cap \partial P(\partial P-$ граница $P)$.

Доказательство этой теоремы также может быть получено с помощью диаграмм Гейла.

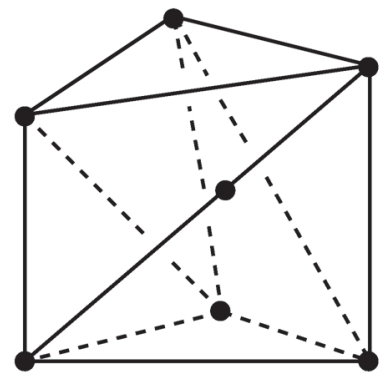

ПРимеР. Рассмотрим невыпукльй многогранник с шестью вершинами, получающийся из треугольной призмы таким вращением верхнего основания относительно нижнего, что каждая боковая грань складьвается в два треугольника с ребром возврата между ними (см. рисунок). Это звездньй многогранник, введенный в работе Шёнхардта [5]. Его нельзя триангулировать без точек Штейнера. Если такую точку вставить внутрь ядра и соединить со всеми вершинами, то получится триангуляция, которая по теореме 2 нерегулярна. Тем не менее, многогранник Шёнхардта можно регулярно триангулировать, если вьвести дополнительную точку на ребро возврата.

Возникает естественный вопрос: верно ли, что всякий невыпуклй многогранник можно регулярно триангулировать после добавления на его ребра точек Штейнера, число которых полиномиально зависит от $n$ ? Н.Е. Мнёв (частное сообщение) утверждает, что это верно, если разрешить добавлять точки Штейнера не только на ребра, но и на грани.

\section{СПИСОК ЛИТЕРАТУРЫ}

[1] И. М. Гельфанд, А.В. Зелевинский, М.М. Капранов // Алгебра и анализ. 1990. T. 2. №3. C. 1-62. [2] L. J. Billera, P. Filliman, B. Sturmfels // Adv. in Math. 1990. V. 83. Р. 155-179. [3] Л. Г. Хачиян // Докл. АН СССР. 1979. Т. 244. № 5. С. 1093-1096. [4] J. Ruppert, R. Seidel // Discrete Comput. Geom. 1992. V. 7. P. 227-253. [5] E. Schönhardt // Math. Ann. 1928. V. 98. P. 309-312.

Санкт-Петербургский государственный университет

E-mail: anton@ap9560.spb.edu, romanov@yr2008.spb.edu

Принято редколлегией 23.05 .2002 